\title{
O PLURALISMO JURÍDICO E OS MEIOS EXTRAESTATAIS DE ADMINISTRAR CONFLITOS
}

\section{LEGAL PLURALIM AND EXTRA-STATE FORMS OF MANAGING CONFLICTS}

\section{EL PLURALISMO JURÍDICO Y LOS MEDIOS EXTRAESTATALES DE ADMINISTRAR CONFLICTOS}

\section{Fabiana Marion Spengler ${ }^{1}$}

Licença CC BY:

Artigo distribuído sob os termos Creative Commons, permite uso e distribuição irrestrita em qualquer meio desde que o autor credite a fonte original.

\begin{abstract}
Resumo: Diante do cenário de crise das funções estatais o artigo que agora se apresenta possui como tema central o pluralismo jurídico, questionando se é possível existir a regulação autônoma das relações por parte de grupos sociais e se essa pluralidade se origina na retração do Estado e na sua imobilidade face às grandes mudanças produzidas pela modernidade. $\mathrm{O}$ objetivo do presente texto é analisar o pluralismo jurídico como possibilidade de regulação autônoma dos grupos sociais, enquanto direito social produzido pela sociedade, muitas vezes alheio ao Estado. Para fins de cumprir com o proposto o método de abordagem utilizado foi o dedutivo e o método de procedimento foi o monográfico. Em linhas gerais, as principais conclusões apontam para o fato de que o pluralismo jurídico é uma das consequências da retração do Estado diante do surgimento de novas forças (paralelas) que fomentam a criação de um direito supra estatal. Então, a tendência é o aumento da organização e da aplicação de regras criadas pelo cidadão objetivando o tratamento de conflitos
\end{abstract}

Palavras-chave: Pluralismo jurídico; Estado; Conflito.

Abstract: In consideration of the State's scenario of crisis, this article takes legal pluralism as its central theme, questioning whether it is possible to have autonomous regulation of relations by social groups and, whether this plurality originates in the retraction of the State and its immobility before the great changes provoked by modernity. Therefore, this paper aims to analyze legal pluralism as a possibility of autonomous regulation of social groups, as a social right produced by society, often unrelated to the State. In order to comply with the proposed study, the deductive research method

$1 \quad$ Pós-doutora em Direito pela Università degli Studi di Roma Tre, em Roma, na Itália, com bolsa CNPq (PDE). Doutora em Direito pelo programa de Pós-Graduação stricto sensu da Universidade do Vale do Rio dos Sinos - UNISINOS - RS, com bolsa Capes, mestre em Desenvolvimento Regional, com concentração na área Político Institucional da Universidade de Santa Cruz do Sul - UNISC - RS, docente dos cursos de Graduação e Pós Graduação lato e stricto sensu da UNISC; Bolsista de Produtividade em Pesquisa (Pq2) do CNPQ; líder do Grupo de Pesquisa "Políticas Públicas no Tratamento dos Conflitos" certificado pelo CNPq; coordenadora do projeto "O terceiro e o conflito: o mediador, o conciliador, o juiz, o árbitro e seus papeis políticos e sociais, financiado pela Fundação de Amparo à Pesquisa do Estado do Rio Grande do Sul, no Edital 02/2017, PqG FAPERGS, Pesquisador Gaúcho, processo n¹7/2551-0001169-4; coordenadora e mediadora do projeto de extensão: "A crise da jurisdição e a cultura da paz: a mediação como meio democrático, autônomo e consensuado de tratar conflitos" financiado pela Universidade de Santa Cruz do Sul - UNISC; autora de diversos livros e artigos científicos, e-mail: fabiana@unisc. 
was used, and the procedural method used was a monography. The main conclusion drawn is that legal pluralism is one of the consequences of the retraction of the State before the new power, which leads to the creation of a supra-state right. Thus, the tendency is for the organization and the application of rules created by the citizens to increase, in order to deal with conflicts.

Keywords: Legal pluralism; State; Conflict.

Resumen: Delante del escenario de la crisis de las funciones estatales el artículo que ahora se presenta posee como tema central el pluralismo jurídico, cuestionando si es posible existir la regulación autónoma de las relaciones por parte de grupos sociales y si esa pluralidad se origina en la retracción del Estado y en su inmovilidad delante a los grandes cambios producidos por la modernidad. El objetivo del presente texto es analizar el pluralismo jurídico como posibilidad de regulación autónoma de los grupos sociales, en cuanto el derecho social producido por la sociedad, muchas veces ajeno al Estado. Para cumplir con lo propuesto, el método de abordaje utilizado fue el deductivo y el método de procedimiento fue el monográfico. En líneas generales, las principales conclusiones apuntan para el hecho de que el pluralismo jurídico es una de las consecuencias de retracción del Estado delante del surgimiento de nuevas fuerzas (paralelas) que promueven la creación de un derecho supra estatal. Entonces, la tendencia es el aumento de la organización y de la aplicación de reglas creadas por el ciudadano objetivando el tratamiento de conflictos.

Palabras clave: Pluralismo jurídico; Estado; Conflicto.

\section{INTRODUÇÃO}

Muito tem sido dito a respeito da necessária transformação do Estado, proposta que possui aspectos relevantes, delimitados pela crise (ruptura) que o assola e a consequente dificuldade/ impossibilidade de manutenção das coisas segundo o status quo ante (continuidade). Assim, quando se fala em crise do Estado, é preciso que se analise a transformação observada nas relações entre as funções estatais tradicionais quando, aparentemente, cada uma delas se projeta sobre aquilo que tradicionalmente seria atribuição característica da outra. Hipótese diversa é aquela apontada para justificar (mesmo que parcialmente) a crise de soberania, que mostra um Estado fraco, diluído, aberto, permeado por espaços conflituosos que ele mesmo não dá conta de resolver.

De fato, a atual crise do Estado se caracteriza por um progressivo organizar-se sobre a base de interesses particulares da sociedade que vai perdendo cada vez mais o seu caráter "atomístico 2" enquanto crescem as deficiências dos meios jurídicos e institucionais que ela mesma possui para fazer refletir e valer a sua estrutura no seio estatal. Essa deficiência explica porque aquelas associações e grupos de indivíduos que (por sua natureza e por seus próprios interesses) não deveriam voltarse contra o Estado, fazem causa comum com aqueles que propõem uma radical e revolucionária transformação dos poderes públicos. A principal consequência desse movimento é a desconfiança com relação às instituições estatais. Essa desconfiança causa o enfraquecimento e a fragmentação

2 A utilização da palavra atomismo aqui tem conexão com o sistema segundo o qual o universo foi formado pela combinação fortuita dos átomos. É a doutrina na qual os corpos são constituídos de partículas indivisíveis e irredutíveis. 
estatal gerando um pluralismo de ações e um pluralismo funcional ${ }^{3}$. A fragmentação estatal acontece de forma paralela à fragmentação dos poderes públicos, cujas consequências têm ênfase no âmbito do ordenamento jurídico - suas fontes se tornam plurais - e na multiplicação dos loci de poder. Assiste-se a um "policentrismo" 4 dos ordenamentos gerais, o que causa dúvidas, inclusive, sobre a manutenção de conceitos até então postos e considerados irretorquíveis, dentre eles a exatidão sobre o que são entes públicos ${ }^{5}$. Na mesma seara, a dificuldade também existe quanto à individualização de setor público estatal e não estatal, e quanto à recondução ao endereço do governo (ou dos outros órgãos representativos) os vários poderes públicos não estatais.

Diante desse estreito resumo do cenário e das dificuldades do Estado desenvolver o papel a ele atribuído, o artigo que agora se apresenta possui como tema central o pluralismo jurídico ${ }^{6}$, questionando se é possível existir a regulação autônoma das relações por parte de grupos sociais e se essa pluralidade se origina na retração do Estado e na sua imobilidade face às grandes mudanças produzidas pela modernidade. A principal hipótese de pesquisa responde de modo afirmativo a interrogação objeto de estudo.

Por conseguinte, o objetivo do presente texto é analisar o pluralismo jurídico como possibilidade de regulação autônoma de cada grupo social, enquanto direito social produzido pela sociedade, muitas vezes alheio ao Estado. Desse modo, não será objeto de análise o pluralismo de ordenamentos jurídicos ${ }^{7}$ dentro de um mesmo Estado, bem como não se analisará os meios pelos quais os conflitos entre esses ordenamentos são solucionados ${ }^{8}$. Nesse mesmo sentido, o pluralismo político/partidário não será abordado, não obstante ser assunto importante, porém a margem do tema principal do presente artigo ${ }^{9}$.

A delimitação do tema assim proposta tem por base as considerações de Antonio Carlos Wolkmer, ao afirmar que o pluralismo pode ser interpretado de formas diferentes, especialmente nas últimas décadas. Na concepção do autor o pluralismo pode ser: a) primeiramente, a defesa de

3 STRECK, L. L.; MORAIS, J. L. B. de. Ciência política e teoria geral do Estado. 8. ed. Porto Alegre: Livraria do Advogado, 2013.

4 CASSESE, S. 2002. La crisi dello Stato. Toma-Bari: Laterza \& Figli Spa, 2002, p. 22.

5 De fato, quando a figura do ente público entra em crise, é necessário reconhecer que são tantas definições/noções quantos entes públicos se conhece. Nestes termos, se faz importante a leitura de Gerin (1974).

6 Quanto à forma de abordagem do pluralismo jurídico, se faz necessário dizer que ela será feita muito mais enquanto "pluralismo de fontes do direito" do que no sentido de "pluralismo de ordenamentos jurídicos". Isso porque o que se pretende é abordar as várias formas de produção do direito surgidas da retração estatal, que nada mais é do que uma das consequências da crise funcional. Assim, não se pretende analisar o pluralismo de ordenamentos jurídicos e os seus conflitos, mas o pluralismo de fontes do direito.

$7 \quad$ Nesse sentido, é importante a leitura de Modugno (1985).

8 É por isso que não será objeto de aprofundamento o pluralismo jurídico como teoria dualista na qual se observam dois tipos de ordenamento: o estatal e o internacional, e sim o pluralismo enquanto pluralidade de fontes extraestatais de direito. Além disso, o eixo norteador do presente item é o pluralismo contemporâneo, suas causas, suas limitações, críticas e objeções. Consequentemente, não se analisará as vertentes da comunidade pluralista produzidas por Aristóteles, Edmund Burke, Visconde Louis de Bonald, Georg Wilhelm Friederich Hegel, Aléxis de Tocqueville, Felicite Robert de Lamennais, Émile Durkheim e Max Weber, dentre tantos outros. Ver Nisbet (1999).

9 Importa ressaltar que, pelos motivos anteriormente elencados, também não será objeto de análise a distinção entre as várias formas de pluralismo feita por Bobbio, dentre as quais pode-se citar: o pluralismo socialista, o pluralismo democrático e o pluralismo cristão-social. Conforme Bobbio (1999). 


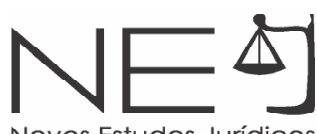

uma pluralidade policêntrica infrajurídica, [...] uma vez que a estrutura do Direito imposta pelo poder político estatal desenvolve relações diversas, complementares ou antagônicas com os múltiplos sistemas do infradireito; b) uma segunda concepção de pluralismo jurídico expressa a realidade emergente dos fenômenos multiétnicos e multiculturais, próprio das sociedades marcadas pelo forte surto migratório; c) a terceira concepção é a do pluralismo jurídico mercatório gerado pelas mudanças no cenário globalizado, pelas crises das sociedades desorganizadas e atomizadas e pelo processo de ampliação dos espaços de normatividade supranacionais; d) a quarta concepção é a do pluralismo jurídico das práticas participativas comunitárias, expressão das chamadas experiências de direito informal, direito insurgente, direito paralelo ou direito alternativo ${ }^{10}$. Vale ressaltar que, com exceção da terceira interpretação, todas as demais serão objeto de abordagem nesse artigo uma vez que dizem respeito as práticas não institucionalizadas de tratamento dos conflitos.

Para fins de cumprir com o proposto o método de abordagem utilizado foi o dedutivo, partindo da relação entre argumentos gerais, denominados premissas, para argumentos particulares, até se chegar a uma conclusão. Como método de procedimento foi utilizado o método monográfico, a partir da leitura e fichamentos de fontes bibliográficas ligadas ao tema da pesquisa.

\section{PLURALISMO JURÍDICO E SUAS ORIGENS}

O pluralismo jurídico, enquanto pluralismo de fontes, é uma das consequências do fato de que o Estado já não aparece como ator principal na elaboração e aplicação legislativa, surgindo, paralelas a ele, novas forças que apontam para o nascimento do direito supra estatal ${ }^{11}$. Na verdade, trata-se de uma reflexão do aparecimento de forças supra estatais advindas da autodeterminação de organizações sociais e de sua intensa participação nas decisões dos órgãos públicos. Assim, a crise de racionalidade formal e as novas condições globais das forças produtivas capitalistas, que permeiam a complexa cultura burguesa de massas, estendem-se ao saber sacralizado e hegemônico das estruturas lógicoformais que mantêm os envelhecidos padrões de legalidade estatal. Daí a perspectiva de um "novo" pluralismo compreendido como marco de ruptura e denúncia dos mitos sacralizados do instituído e como expressão mais direta dos reais interesses e exigências da experiência interativa histórico-social ${ }^{12}$.

Na linguagem política, pluralismo é o termo utilizado para definir uma concepção que propõe como modelo social uma composição de vários grupos ou centros de poder, mesmo que em conflito entre si, aos quais é atribuída a tarefa de limitar, controlar e contrastar, até o ponto de eliminar, o centro de poder dominante, historicamente identificado com o Estado. Nesse sentido que o

10 WOLKMER, A.C. Pluralismo jurídico. In: BARRETO, Vicente de Paulo. Dicionário de Filosofia do Direito. Rio de Janeiro/São Leopoldo: Renovar/Editora Unisinos, 2006, p.638.

11 Sobre o tema sugere-se a leitura de SPENGLER, Fabiana Marion. Os (des)caminhos do Estado e da Jurisdição. Santa Cruz do Sul: Essere nel Mondo, 2017.

12 WOLKMER, A.C. Pluralismo jurídico: fundamentos de uma nova cultura no direito. 3. ed. São Paulo: Alfa Omega, 2001. 
pluralismo é visto como uma forma de oposição à tendência de concentração e unificação de poder, própria da formação estatal moderna.

Outrossim, o Pluralismo opõe-se à teoria tradicional da separação dos poderes. Esta propõe a divisão do poder do Estado em sentido horizontal, enquanto a ideia contida no Pluralismo traz a perspectiva da divisão vertical ${ }^{13}$. Essa definição política de pluralismo dá vazão a descrições ambíguas, ou, conforme Norberto Bobbio, emotivamente polivalentes, uma vez que:

Pluralismo evoca positivamente um estado de coisas no qual não existe um poder monolítico e no qual, pelo contrário, havendo muitos centros de poder, bem distribuídos territorial e funcionalmente, o indivíduo tem a máxima possibilidade de participar na formação das deliberações que lhe dizem respeito, o que é a quintessência da democracia. ${ }^{14}$

Porém, negativamente, o pluralismo gera a imagem:

De um estado de coisas caracterizado de um lado pela falta de um verdadeiro centro de poder e, de outro, pela existência de inúmeros centros de poder continuamente em luta entre si e o poder central, ou seja, pela prevalência dos interesses particulares, setoriais e grupais sobre o interesse geral, das tendências centrífugas sobre as centrípetas, pela fragmentação do corpo social em vez de sua benéfica desarticulação. ${ }^{15}$

A existência do pluralismo jurídico, chamado de pré-moderno, remonta a aurora da sociedade civilizada quando já se percebiam sinais da influência de vários atores na elaboração e aplicação da lei, especialmente na Europa, onde em torno do ano 1000 verifica-se uma grande proliferação de povos, línguas, crenças, costumes e, consequentemente, regras de Direito ${ }^{16}$.

Porém, o aprimoramento das técnicas de comércio e a dinâmica das trocas empreendidas deram origem a rotas marítimas e terrestres. Com o aparecimento de constantes guerras e batalhas, a transformação dos costumes e, principalmente, dos atores envolvidos nas trocas acontecia com frequência, sendo que não eram raras as vezes nas quais os invasores impunham aos povos rendidos os seus usos e costumes como meio de dominação e poder.

Ocorre que, com o fim dos conflitos e a volta da segurança (ainda que passageira), com o crescimento urbano e o incremento do comércio, aumentaram as exigências de uma regulamentação própria que veio, então, juntar-se aos sistemas jurídicos já existentes e nascidos na esteira da pluralidade de culturas que de alguma forma os tinha influenciado. No entanto, com a ascensão da Igreja e do clero, com a imposição de sua lei canônica e, posteriormente, com a transferência

13 BOBBIO, N. Pluralismo. In: BOBBIO, N.; MATTEUCCI, N.; PASQUINO, G. Dicionário de Política. Tradução Carmen V. Varriale et al. Coordenador e tradutor João Ferreira; revisão geral João Ferreira e Luís Guerreiro Pinto Cascais. 12. ed. Brasília: Editora Universidade de Brasília, 2004.

14 BOBBIO, N. As ideologias e o poder em crise. Tradução de João Ferreira. 4. ed. Brasília: UnB, 1999, p.23-24.

15 BOBBIO, N, As ideologias e o poder em crise, p.23-24.

16 Nesse sentido, é importante a leitura de Nisbet (1999). 


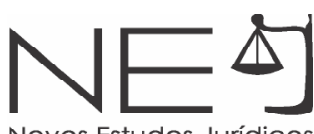

desse poder aos "príncipes temporais", o pluralismo anterior estava fadado a desaparecer. E assim aconteceu, a unificação do Direito eclode no fim da Idade Média com a imposição de uma cultura "nacional", sem fronteiras, cada um esforçando-se para "dominar os outros" e impor sua autoridade: isso também faz parte da marcha rumo ao universalismo, cheia de tentativas mais ou menos bem sucedidas de imperialismo ${ }^{17}$.

O pluralismo da Idade Média, aliás, foi revestido de "funções, autoridade e submissões. Havia um grande número de cada uma destas e, apesar do conflito quase incessante - a acreditar nos números dos historiadores -, não há contradição entre os eventos do pluralismo e o conflito." ${ }^{18}$. Assim, a "necessidade, e mesmo o valor do conflito - em grau moderado, pelo menos -, é reconhecida por todos os expoentes do pluralismo." ${ }^{19}$.

Assim como no cenário internacional, o Brasil viveu um pluralismo primeiramente cultural que depois desenvolveu-se, podendo ser vislumbrado também no âmbito jurídico, desde sua colonização até os dias atuais. O Direito português teve supremacia na base do Direito pátrio. Porém não se pode perder de vista a contribuição de outros povos (como os indígenas), que se mostrou relevante para a construção da cultura brasileira, e que não refletiu a mesma importância quanto à origem do Direito brasileiro, em função de que os nativos não conseguiram impor suas leis, participando mais "na humilde condição de objeto de direito real", ou seja, objetos de proteção jurídica. O mesmo aconteceu com relação ao negro ${ }^{20}$.

Nesse contexto, percebe-se que, desde o início da colonização, além da marginalização e do descaso pelas práticas plurais de um Direito nativo e informal, a ordem normativa oficial implementava, gradativamente, as condições necessárias para institucionalizar o projeto expansionista lusitano. Ainda na época da colonização, o Direito oficial (aqui considerado como aquele que emanava do Estado através de leis positivadas) era quase nenhum, utilizando-se ainda dos costumes locais. Então, à medida que era reconhecida a religião católica como religião oficial do Estado, admitia-se a existência de um certo tipo de pluralismo jurídico e consagrava-se a supremacia do direito paralelo da Igreja (o Direito canônico) sobre o direito oficial do Estado (o Direito do império). Mesmo assim, não se pode esquecer que "tratava-se de um pluralismo jurídico ideologicamente conservador e elitista que reproduzia tão-somente a convivência das forças dominantes, ou seja, entre o direito do Estado e o direito da igreja." 21.

Observa-se que o pluralismo jurídico - que pode ser, a partir de Wolkmer (2001)22, designado como a multiplicidade de práticas jurídicas existentes num mesmo espaço sócio-político, interagidas

17 ARNAUD, A. J. O Direito entre Modernidade e Globalização - Lições de Filosofia do Direito e do Estado. Tradução de Patrice Charles Wuillaume. Rio de Janeiro: Renovar, 1999a, p. 67.

18 NISBET, R. Os filósofos sociais. Tradução de Yvette Vieira Pinto de Almeida. Brasília: UnB, 1999, p. 381.

19 NISBET, R, Os filósofos sociais, p. 391.

20 WOLKMER, A. C. Instituições e pluralismo na formação do direito brasileiro. Teoria do Direito e Estado. (Org. Leonel Severo Rocha). Porto Alegre: Sérgio Antonio Fabris, 1994, p. 9-10.

21 WOLKMER, A. C, Instituições e pluralismo na formação do direito brasileiro, p. 13.

22 WOLKMER, A.C, Pluralismo jurídico: fundamentos de uma nova cultura no direito. 
por conflitos ou consensos, podendo ser ou não oficiais e tendo sua razão de ser nas necessidades existenciais, materiais e culturais -, reconhecido no Brasil desde a colonização como fruto das várias culturas aqui existentes e de seus costumes, cede à intervenção estatal como ator único, capaz de elaboração legislativa da qual emanam todos os ordenamentos, numa tentativa de vincular o Direito à criação estatal. Conclui-se, então, que o pluralismo jurídico brasileiro trilhou o mesmo caminho verificado na Europa e anteriormente relatado. Partindo da cultura de cada povo, os usos e costumes se espalharam em cada guerra e a cada nova invasão, criando um pluralismo de fontes do Direito que posteriormente cedeu diante da imposição e da universalidade da "lei do mais forte", devidamente codificada, imposta ao cidadão. Desse modo, deixou de ser relevante aos olhos do Estado toda a fonte não oficial de Direito existente até então, independentemente do fato de que esta última poderia, em determinadas circunstâncias, ter mais eficácia do que a primeira.

Paradoxalmente, na atualidade, o "principal núcleo para o qual converge o pluralismo jurídico é a negação de que o Estado seja a fonte única e exclusiva de todo o Direito." ${ }^{23}$. Tal visão advoga a supremacia de fundamentos ético-sociológicos sobre critérios tecnoformais. Assim, "minimizase ou exclui-se a legislação formal do Estado e prioriza-se a produção normativa multiforme de conteúdo concreto gerada por instâncias, corpos, movimentos organizados semiautônomos que compõem a vida social." 24 .

Surge, então, a ideia de "direito social" que Georges Gurvitch propõe ao extrapolar a vinculação ao processo legislativo oficial, alcançando à sociedade a regulação e o controle das decisões em face da relação entre o Direito e a vida social. Disto, importa a referência de Gurvitch, no sentido do direito social se demonstrar como produto da articulação de organizações complexas, bastante semelhantes ao processo discursivo de Habermas, de modo que este direito social poderia, conforme a concepção habermasiana, ser percebido como uma ordem normativa calcada na interação comunicativa de seus atores ${ }^{25}$.

Portanto, o Direito se ampara no reconhecimento coletivo, tornando-se necessário reconhecer que o seu centro de desenvolvimento na época atual ou em qualquer outra "não deve ser procurado nem na lei, nem na jurisprudência ou na doutrina, nem no modo mais geral, num sistema de regras, mas sim na própria sociedade." ${ }^{26}$. Nestes termos, a sociedade legitima o Direito possibilitando a sua normatividade (que pode, então, ser alheia ao Poder Legislativo), viabilizando a manifestação e a interpenetração de "uma pluralidade de ordenações autônomas de agrupamentos particulares, excluído o Estado."27.

23 WOLKMER, A.C., Pluralismo jurídico: fundamentos de uma nova cultura no direito, p. 183.

24 WOLKME, A.C., Pluralismo jurídico: fundamentos de uma nova cultura no direito, p. 183.

25 MORAIS, J. L. B. de. 1997. A idéia de direito social. O pluralismo Jurídico de Georges Gurvitch. Porto Alegre: Livraria do Advogado.

26 GURVITCH, G. 1968. Tratado de Sociologia. 2. ed. Rio de Janeiro: Iniciativas Editoriais, 1968, p. 256.

27 GURVITCH, G, Tratado de Sociologia, p. 256. 
Nessa mesma linha, o Direito é concebido, conforme Eugen Ehrlich ${ }^{28}$, como "produto espontâneo da sociedade", partindo do fato de que a última é formada por organizações bem diversificadas ou associações humanas inter-relacionadas que compreendem associações, grupos, comunidades religiosas, classes, partidos políticos e famílias, dentre outros que interagem entre si e mesmo assim conservam a autonomia parcial ou total diante do Estado. Isso se dá porque cada associação humana elabora sua própria ordem jurídica, sem compromisso com outras formas de organização, podendo a influência ser recíproca, acontecer ou não. Isto posto, o verdadeiro Direito é aquele que pode ser denominado "direito vivo" 29 , que não se prende a doutrinas ou prescrição estatal, acontecendo a partir da "vida concreta das pessoas" e de suas relações entre si e com as mais variadas instituições. A eficácia desse Direito repousa em sanções que, diversamente das estatais, se fundam na pressão coletiva e na própria força que emana das associações coletivas (ameaça de expulsão do grupo, da família, da igreja, do partido, risco de perder o crédito, etc.) e não em uma pena. Afirma-se, portanto, que os complexos normativos podem ser classificados em três categorias. A primeira é a do direito vivo, organizado por grupos associativos, emergente da complexidade social. A segunda se refere ao direito dos juízes, composto por normas utilizadas nos tribunais para decidir casos concretos de litígios e de conflitos, e que se encontra intimamente entrelaçado ao direito estatal, uma vez que é o caminho utilizado para dar cumprimento as suas normas. Por fim, a terceira, que compreende o direito estatal, que depende de um aparelho coativo (Poder Judiciário), emanando ordens de cunho decisório (normas estatais indiretas) e de cunho interventivo (normas estatais diretas) ${ }^{30}$.

Em resumo, perpassa com nitidez, nas considerações de Ehrlich, que a função primordial do Direito não é a resolução dos conflitos, mas a instituição de uma ordem pacífica interna nas relações sociais de qualquer associação humana. Consequentemente, o centro gerador do Direito não se encontra na legislação, na doutrina, na jurisprudência e nem no sistema de regras, e sim na própria sociedade ${ }^{31}$.

O pluralismo sofreu grande impacto com a globalização e seus reflexos em termos econômicos, culturais e principalmente no que diz respeito à soberania dos Estados. Por isso, o termo pluralismo jurídico pode ser resumido dizendo que pluralismo significa a translação das organizações e dos direitos prejudicados para os indivíduos pelas democracias liberais, definindo o Estado pluralista como aquele cuja política e formação de vontade estão influenciadas, quando não dirigidas, pela luta e pelo compromisso entre poderes econômicos e sociais estabelecidos à margem do âmbito estatal ${ }^{32}$.

Esse é o ponto de diferenciação entre a nova ideia de ordenamento advindo do Direito social (conforme a teoria gurvitchiana) e o Direito estatal positivado: trata-se da noção de pessoa coletiva complexa que permite ao primeiro a legitimidade democrática sem ofuscar os grupos e indivíduos que se comportam como atores da ação comunicativa habermasiana, permeada pela construção

28 EHRLICH, E. Fundamentos da sociologia do direito. Brasília: UnB, 1986, p. 27 et seq. e 296.

29 Sobre o tema sugere-se a leitura de Resta (2008).

30 EHRLICH, E, Fundamentos da sociologia do direito.

31 WOLKMER, A.C, Pluralismo jurídico: fundamentos de uma nova cultura no direito.

32 GARCÍA-PELAYO, M. Las transformaciones del Estado contemporâneo. Madrid: Alianza Universidad, 1996, p. 204. 
do consenso na sociedade. Tal ideia torna-se inovadora uma vez que permite a constatação da legitimidade democrática, de modo que esta "seria a própria garantia da vigência e eficácia do direito social"33, não como uma imposição da maioria, mas como resultado de um reconhecimento social, decorrente do processo de articulação comunicativa dos integrantes da sociedade. O tipo de grupo ao qual está atrelado o direito social é que permitirá a expressão de uma verdadeira ordem social sob a forma organizada. Então, é somente através de associações de colaboração e/ou de cooperação não-hierárquicas que se alcançará uma identificação entre aquele direito social formulado pelas camadas inorganizadas e sua consubstanciação sob a forma organizada, conforme Morais (1997) ${ }^{34}$.

A concepção de direito social como resultado de um processo autônomo de autoregulação por parte dos agentes sociais, traduzidos por um sujeito complexo, supera o formalismo do positivismo pela construção de regras efetivamente legitimadas, produto da evolução e da articulação das organizações sociais.

A influência de organizações sociais pode ser perfeitamente compreendida a partir da inserção e da utilização de determinados serviços por parte do cidadão comum, que somente obtê-los-á por sua mediação. Essa dependência existente entre o cidadão e tais organizações muitas vezes é maior que a existente quanto ao próprio Estado. Em suma, dispõe de uma capacidade de cooperação e/ ou de conflito que pode inibir ou determinar as polícias do Estado ${ }^{35}$. Como organizações sociais ocidentais que podem influenciar a formulação e a operacionalização de decisões estatais, pode-se apontar, dentre outros, os partidos políticos, os sindicatos de trabalhadores, as grandes empresas e as organizações empresariais.

\section{O PLURALISMO JURÍDICO E O CENÁRIO GLOBALIZADO ATUAL}

O conceito ampliado de pluralismo jurídico segundo José Eduardo Faria ${ }^{36}$ sofreu consequências a partir das mudanças econômicas. Essas alterações, impostas pelas mudanças econômicas influenciam o Direito estatal e suas fontes, fazendo com que se reproduzam os órgãos de tomada e aplicação de decisões, ultrapassando a esfera estatal e promovendo o renascimento do pluralismo jurídico, pois o surgimento de regras de direito próprias a esses diversos acordos regionais aumenta a complexidade dos sistemas jurídicos dos Estados participantes. Ao lado das normas de direito propriamente ditas, aquelas que se impõem em virtude de pactos e de textos, existe toda uma normatividade que emana das concepções e das vivências dos sujeitos e dos grupos que pertencem a essas comunidades, e que transformam a paisagem da soberania nacional tradicional ${ }^{37}$.

33 MORAIS, J. L. B. de, A idéia de direito social. O pluralismo Jurídico de Georges Gurvitch, p.76

34 MORAIS, J. L. B. de. A idéia de direito social. O pluralismo Jurídico de Georges Gurvitch.

35 MORAIS, J. L. B. de, A idéia de direito social. O pluralismo Jurídico de Georges Gurvitch.

36 FARIA, J. E.; KUNTZ, R, Estado, sociedade e direito: qual o futuro dos direitos? Estado, mercado e justiça na reestruturação capitalista. São Paulo: Max Limonada, 2002.

37 ARNAUD, A.-J. Da regulação pelo direito na era da globalização. Anuário de direito e globalização. A soberania. Programa interdisciplinar Direito e Globalização - UERJ. Coordenação de Celso de Albuquerque Mello. Rio de Janeiro: Renovar, 1999b. 
Portanto, observa-se que a superioridade tradicional do Direito legislado recebe hoje a influência do Direito criado por fontes extraestatais que além de "legislarem", influenciam a aplicação e a interpretação da legislação existente. Consequentemente, "la fonte legislativa, nonostante la proliferazione quantitativa, va incontro ad un sicuro declino qualitativo: sempre più infatti, deve rinunciare al suo originario fondamento decisionistico, di tipo monopolistico, e accettare la contaminazione con nuove forme giuridiche 'attenuanti'"38 falta de instituições legislativas fortes, capazes de criar um Direito durável e coeso, são as principais responsáveis pelo atual pluralismo de fontes cuja legitimação não vem assegurada pelo consenso de uma coletividade.

Na mesma esteira, o pluralismo jurídico contemporâneo passa a ser encarado na perspectiva da sobreposição, articulação, intersecção e interpenetração de vários espaços jurídicos misturados. A própria sociologia jurídica mostra que a história da sociedade é permeada constantemente por situações fáticas que, não estando reguladas, reclamam solução jurídica. Nesses casos, muitas vezes são os tribunais que se vêem instados a dizer o Direito, reconhecendo a existência de instituições e relações jurídicas ou de novos direitos. Paralelamente, o Direito estatal é substituído por instâncias que se situam, conforme a hierarquia tradicional - e em consequência da crise progressiva do Estado -, abaixo dele.

Servem de exemplos o deslocamento da produção jurídica em direção aos poderes privados econômicos, a importância do papel desempenhado pelas corporações, os códigos de conduta privados, o desenvolvimento de um Direito negociado e a jurisdição crescente da normalização técnica. Destarte, acrescenta-se, quanto ao tema, a referência à deslocalização, à descentralização e à desconcentração. Estas, tidas como instâncias in loco, que substituem a autoridade central e soberana destinada a dizer o direito. Como processo de desconexão à autoridade central, ocorre também no que tange à hierarquia das normas caracterizadoras do sistema jurídico existente. Acrescentam-se, ademais, novas formas de conciliação, de mediação e de negociação, inseridas, paulatinamente, no processo judicial do Estado ${ }^{39}$.

É nesse contexto que a grande tendência tem sido tratar as cadeias normativas da "economiamundo", as formas legais transnacionais e a interseção das regras autoproduzidas pelas corporações financeiras e empresariais com o Direito positivo dos Estados-nação a partir do ângulo do pluralismo jurídico. Porém, o Direito Internacional e o pluralismo jurídico sempre foram tratados de modo não prioritário (quando não ignorados ou desprezados por sua natureza "metajurídica") ${ }^{40}$.

É possível dizer que o Direito Internacional tem importante papel na constituição e compreensão do perfil das instituições jurídicas da economia globalizada. Mas ele não o esgota, pois abrange apenas uma parcela dessas instituições, uma vez que se concentra geralmente em torno do Direito

38 ZANGHÍ, C. Diritto delle organizzazioni internazionali. Torino: [s. ed.], 2001, p. 55.

39 ARNAUD, A.-J, Da regulação pelo direito na era da globalização. Anuário de direito e globalização. A soberania. Programa interdisciplinar Direito e Globalização.

40 ARNAUD, A.-J, Da regulação pelo direito na era da globalização. Anuário de direito e globalização. A soberania. Programa interdisciplinar Direito e Globalização, p. 150. 
oficial (códigos, leis, regulamentos, convenções, acordos e tratados internacionais), e não sobre os demais direitos constituídos paralelamente a ele.

Na era econômica do pós-guerra, o ordenamento jurídico do Estado intervencionista, com seus instrumentos regulatórios, consistia no "direito central". Tudo isso porque dispunha de condições efetivas para influenciar e condicionar o "direito da produção" e o produzido no espaço do mercado, graças à dependência das empresas, às barreiras tarifárias, ao protecionismo comercial e aos incentivos, subsídios e créditos oferecidos pelos programas de crescimento e desenvolvimento industrial, e à ampliação das leis de defesa do consumidor. Mas, atualmente, na tão aclamada era da economia globalizada, "é o 'direito da produção' que parece exercer essa centralidade, fixando os parâmetros e os limites estruturais das transformações do Direito positivo (especialmente no âmbito do Direito econômico, trabalhista e fiscal)." ${ }^{41}$. Portanto, há uma série de questões que exigem o olhar dos Estados e que muitas vezes não encontram previsão legal, dentre elas os problemas ligados ao clima, ao ambiente, à segurança ou à economia, que não podem ser tratados de forma isolada como se fossem de responsabilidade deste ou daquele Estado-nação, pois possuem ligação indubitável com o equilíbrio mundial.

Assim, a segurança global encontra-se transformada. Antes centrada tradicionalmente na segurança dos Estados, ela se orienta rumo à segurança de todas as pessoas e do conjunto dos habitantes do planeta. As dificuldades se instalam no concernente ao estabelecimento de fronteiras entre a "segurança no sentido militar, e a segurança vinculada às considerações econômicas ou humanitárias. A estratégia sugerida é uma estratégia preventiva 'compreensiva' [...]. Ela está centrada em causas ao mesmo tempo políticas, sociais, econômicas e ambientais." ${ }^{42}$. Porém, não se pode esquecer que "é verdade que muitas crises têm por origem a pobreza e o subdesenvolvimento" 43 . Diante de tais fatos, a globalização do tema da segurança, descolando-se progressivamente da soberania dos Estados-nações, traz mudanças do próprio sentido do conceito, a ponto de criar um novo conceito, o da "segurança humana", que visa atacar as ameaças crônicas à dignidade: a fome, as doenças, a repressão. Consequentemente, "os Estados são levados, em nome da segurança global, a participar da antecipação e da prevenção das crises, mesmo que, no plano individual, não tenham a menor vontade de se imiscuir com o que se passa do lado de fora de suas fronteiras." 44 .

Como consequência dos fatores analisados anteriormente, o Direito positivo do Estadonação não dispõe mais de condições para se organizar quase exclusivamente sob a forma de atos unilaterais, transmitindo de modo "imperativo" as diretrizes e os comandos do legislador. Diante dessa dificuldade, as fontes jurídicas extraestatais ganham força como possíveis produtoras de Direito. Essas fontes se disseminam em todos os segmentos, do social ao econômico, representando

41 ARNAUD, A.-J, Da regulação pelo direito na era da globalização. Anuário de direito e globalização. A soberania. Programa interdisciplinar Direito e Globalização, p. 164.

42 ARNAUD, A.-J, Da regulação pelo direito na era da globalização. Anuário de direito e globalização. A soberania. Programa interdisciplinar Direito e Globalização, p. 32-33.

43 ARNAUD, A.-J, Da regulação pelo direito na era da globalização. Anuário de direito e globalização. A soberania. Programa interdisciplinar Direito e Globalização, p. 32-33.

44 ARNAUD, A.-J, Da regulação pelo direito na era da globalização. Anuário de direito e globalização. A soberania. Programa interdisciplinar Direito e Globalização, p. 32-33. 


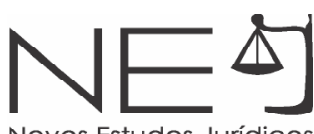

uma pluralidade. Justamente por seu caráter radical, que exclui parcial ou totalmente a presença do Estado, o pluralismo sofre duras críticas, as quais apontam também para a sua fragmentação incontida que induz à desagregação anárquica, à sua redução ao poder de decisão de elites econômicas, à ameaça do autoritarismo de grupos sobre indivíduos ou ao monopólio de alguns corpos intermediários sobre os interesses majoritários da coletividade. Tais corpos são qualificados a partir da leitura de Bobbio ${ }^{45}$, como "grupos sociais que se interpõem entre o indivíduo e o Estado" e tendem a considerar bem organizada a sociedade em que os grupos sociais gozam de uma certa autonomia no que diz respeito ao poder central e têm o direito de participar, mesmo concorrendo entre si, da formação das deliberações coletivas.

Nesse sentido, Wolkmer ${ }^{46}$ se posiciona de modo contrário ao pluralismo desenfreado implementado pelo surto "neoliberal" e pela retórica "pós-moderna" que favorecem ainda mais o interesse de segmentos privilegiados e de corporações privatistas, coniventes com as formas mais avançadas de exclusão, concentração e dominação do grande capital. O oposto a esse pluralismo é o pluralismo de "sujeitos coletivos" baseado em uma proposta inovadora: construir uma hegemonia que contemple o equilíbrio entre o predomínio da vontade geral sem negar o pluralismo dos interesses particulares. Essa proposição tem em vista a construção de um bloco histórico marcado pelo consenso, no qual seriam articulados os diferentes interesses sociais, políticos, econômicos, ideológicos, jurídicos. Esse processo somente se tornará exitoso se fundado na democracia participativa interclassista, resgatando alguns princípios da cultura política ocidental, dentre os quais: direito das minorias, direito à diferença e à autonomia, à tolerância e ao compartilhamento do poder para limitálo e socializá-lo ${ }^{47}$. Nesta linha de raciocínio, o pluralismo do medievo vigorava justamente porque "os produtores de direito eram uma pluralidade de ordenamentos jurídicos que frequentemente(sic) conviviam em um mesmo território de um modo harmonioso; as autonomias, na sua relatividade, se respeitavam mutuamente." Assim, existiam os direitos ditos "particulares - leis de princípios locais, estatutos das cidades e do campo, costumes feudais, costumes agrários, costumes e ainda estatutos mercantis -, com um particularismo jurídico minutíssimo"48.

Assim, discorrendo sobre limites ou objeções ao pluralismo jurídico, é preciso considerar que certas funções não podem ser exercidas por indivíduos ou por associações particulares sem grave perigo para a ordem social e sem o aniquilamento do próprio Estado. Há funções que são inerentes à soberania estatal, próprias de seu conteúdo e que não podem ser objeto de delegação: aquelas de defesa do território, de segurança interna, de legislação e jurisdição ${ }^{49}$.

45 BOBBIO, N. As ideologias e o poder em crise. Tradução de João Ferreira. 4. ed. Brasília: UnB, 1999, p. 30.

46 WOLKMER, A.C, Pluralismo jurídico: fundamentos de uma nova cultura no direito, p. 182.

47 COUTINHO, C. N. Notas sobre o pluralismo. Conferência apresentada no Encontro Nacional da Associação Brasileira de Ensino do Serviço Social. [S.I.;s.n.], 1990.

48 GROSSI, Paolo. Da sociedade de sociedades à insularidade do estado entre medievo e idade moderna. Revista Seqüência, $n^{\circ}$ 55, p. 9-28, dez. 2007.

49 REALE, M. Teoria do Direito e do Estado. 4. ed. São Paulo: [s. ed.], 1984. 
Entretanto, o pluralismo jurídico que se contrapõe ao monismo estatal revela suas vantagens, especialmente quando o critério é a eficácia apontando para a possibilidade de:

Afirmar a primazia de interesses que são próprios a cada grupo predominante; b) manter o equilíbrio entre grupos iguais (por exemplo, o direito dos nativos com relação ao direito do invasor); c) propiciar a especificidade das instituições (com liberdade para optar, em determinadas circunstâncias, pelo direito mais conveniente) e resguardar sua independência (imunidades diplomáticas com relação ao direito local); d) favorecer a descentralização jurídica; e) propiciar o desenvolvimento econômico (condições de igualdade no processo produtivo) ${ }^{50}$.

Como tal, o objetivo do pluralismo jurídico não é única e exclusivamente negar ou minimizar o Direito estatal, mas reconhecer que este é apenas uma das muitas formas jurídicas que podem existir na sociedade. Assim, o pluralismo cobre não somente práticas independentes ou semi-autônomas, com relação ao poder estatal, como também práticas normativas oficiais/formais e práticas nãooficiais/informais. Por isso, o pluralismo pode ter como meta práticas normativas autônomas e autênticas geradas por diferentes forças sociais ou manifestações legais plurais e complementares, reconhecidas, incorporadas e controladas pelo Estado. ${ }^{51} \mathrm{Em}$ suma, o pluralismo jurídico aqui discutido como possibilidade de co-existência de diversas fontes do Direito dentro de uma mesma sociedade civil organizada pode ser traduzido como meio de - num determinado espaço social periférico marcado por conflitos, privações e reivindicações - assegurar a denúncia, a contestação, a ruptura e a implementação de "novos" direitos.

\section{O CONFLITO, O CONSENSO E O PLURALISMO DAS PRÁTICAS JURÍDICAS EXTRAESTATAIS}

Atualmente, o Direito oficial apresenta um elevado grau de institucionalização da função jurídica, que se tornou especializada, autônoma, burocrática e sistematizada, apontando tarefas rigidamente definidas e hierarquizadas. Tais características trazem como consequências a padronização e a impessoalização de procedimentos, a falta de celeridade e, por último, a ineficácia na aplicação da lei em determinados litígios. Exemplo desta ineficácia é a utilização da legislação e da jurisdição tradicional em povos de cultura própria tais como os indígenas. Assim, o "judiciário e o executivo podem até referendar direitos indígenas, no entanto, o ponto de vista e a temporalidade dos povos indígenas parece não ter lugar na rotina processual jurídica nem, tampouco, nas decisões administrativas e políticas públicas. 52" À medida que o Estado e o direito legislado perdem espaço (por sua ineficiência, inaplicabilidade e lentidão), o direito inoficial ganha forças como meio de tratamento de conflitos. Na verdade, se assiste a um gradativo abandono do Direito "como ele é" para se atribuir valor a um novo direito, oficialmente não legitimado. ${ }^{53}$

50 WOLKMER, A.C, Pluralismo jurídico: fundamentos de uma nova cultura no direito, p. 222.

51 WOLKMER, A.C, Pluralismo jurídico: fundamentos de uma nova cultura no direito.

52 SANTOS. Jorge Luis Ribeiro dos. Povos indígenas, Direito e Estado: rompendo cânones do integracionismo jurídico. Revista Novos estudos Jurídicos - NEJ, v. 20, nº 1(jan/abr. 2015).

53 MARRA, R. Max Webber: razionalità formale e razionalità materiale del diritto. In: Sociologia del diritto. Rivista quadrimestrale fondata da Renato Treves. Università Degli Studi di Milano. Milano, XXXII/2005/2-3, p. 69. 
Esse novo espaço surge como uma espécie de "estado de exceção personalizado"54, aplicado, sobretudo às categorias sociais mais pobres que vivem em subculturas completamente estranhas ao Direito institucionalizado, muitas vezes lançando mão da força para o tratamento dos conflitos. O Estado contemporâneo tem ao seu serviço o monopólio da violência legítima. Apoiado em tal monopólio o direito do Estado procede à consolidação (muitas vezes contraditória) das relações sociais, gerindo os conflitos de modo a mantê-los dentro de níveis tensionais toleráveis do ponto de vista da dominação que ele reproduz. Ademais, Castells ${ }^{55}$ propõe que, atualmente, visando à manutenção do monopólio da violência legítima, o Estado tem lançado mão de mecanismos tecnológicos de vigilância na tentativa de aumentar seu poder de repressão, o que ameaça a privacidade do cidadão. No entanto, uma tendência mais profunda vem surgindo, efetivamente minando o poder do EstadoNação: a difusão cada vez maior da capacidade de vigilância e do potencial de violência externa às instituições do Estado e além das fronteiras da nação.

Ocorre que, da mesma forma, pode-se observar que, se o trabalho da polícia vem sendo facilitado pelas novas tecnologias, tornou-se também extraordinariamente complicado pela sofisticação semelhante, por vezes muito superior, o uso das novas tecnologias pelo crime organizado (por exemplo, emprego de aparelhos que interferem na comunicação da polícia, conexões eletrônicas, acesso a registros de computadores, etc.). Deste modo, o Estado se torna tão vigiado quanto vigiante e perde, gradativamente, a sua capacidade de repressão. Nesse sentido, de "Grande Irmão", vivemos a era das "Irmãzinhas" 56 . Entretanto, esse monopólio da força estatal vem se esfacelando. O Estado, ente que reivindicava para si os meios de coerção oficiais de determinado território, agora encontra dificuldades de "ordenar", ou seja, de produzir ordem. Tal tarefa lhe é atribuída justamente porque para seu desempenho se faz necessário um aparelho burocrático hierárquico capaz de reunir e concentrar esforços. Cada vez mais se assiste à proliferação de direitos ditos inoficiais que têm berço, quase sempre, na falta de atenção do Estado para com os direitos fundamentais do cidadão. Então, "adquirem legitimidade os sujeitos sociais que, por sua ação libertadora, edificam uma nova cultura societária de base, cujos direitos insurgentes são a expressão mais autêntica da satisfação das carências e das necessidades humanas fundamentais." ${ }^{57}$.

Mas não é qualquer grupo social que gera "direitos" autênticos. Torna-se essencial a distinção entre grupos comprometidos com as causas do "justo", do "ético" e do "bem comum" de grande parcela da comunidade e grupos sociais identificados com a manutenção dos privilégios, a dominação e a oposição a qualquer mudança. O conteúdo valorativo de uma manifestação normativa informalizada e não oficial é muito relativo, podendo ser moralmente correto ou não ${ }^{58}$. A partir da análise da ética e da moral do grupo social, é possível verificar se temos um direito

54 CAPELLA, J. R. Fruto Proibido: uma aproximação histórico-teórica ao Estudo do Direito e do Estado. Porto Alegre: Livraria do Advogado, 2002, p. 277.

55 CASTELLS, M. $O$ poder da identidade. A era da informação: economia, sociedade e cultura. Tradução de Klauss Brandini Gerhardt. 3. ed. São Paulo: Paz e Terra, 1999.

56 CASTELLS, M. O poder da identidade. A era da informação: economia, sociedade e cultura, p. 350.

57 WOLKMER, A.C. Pluralismo jurídico: fundamentos de uma nova cultura no direito. p. 323.

58 WOLKMER, A.C. Pluralismo jurídico: fundamentos de uma nova cultura no direito, p. 324. 
extraoficial legítimo ou um direito marginal.

Paralelamente, pode-se encontrar os movimentos/grupos sociais não identificados com as ações civis e políticas justas, e com os interesses do povo espoliado, marginalizado e oprimido, cuja legitimidade é questionada uma vez que:

Nem toda manifestação legal não-estatal ou nem todo 'direito' aí produzido pode ser justo, válido e ético, pois um corpo social intermediário ou grupo dirigente qualquer pode criar regras perversas, objetivando atender interesses contrários à comunidade, expressando diretamente intentos de minorias identificadas com o poder, a dominação, a ambição, a exploração e o egoísmo. ${ }^{59}$.

É nesse sentido que a "ausência de eticidade e do valor 'justo' esvaziam a legitimidade desse "direito"60. Assim, não são raras as oportunidades nas quais impera a lei do mais forte, ou seja, daquele que usa a violência para fazer valer o seu código e impor as suas regras, surgindo justamente da "imposição da lei do mais forte nas áreas periféricas inexpugnáveis sob controle do crime organizado e do narcotráfico [...] o que, na prática, revela-se um contra-direito." 61.

O cerne da questão talvez esteja na crise de legitimidade estatal, consequência da crescente fragmentação e diversificação dos interesses sociais que resultam na agregação de tais interesses sob a forma de entidades (re)construídas. Assim, ao mesmo tempo que múltiplas identidades submetem ao Estado suas reivindicações, exigências e desafios da sociedade civil, nasce a crise de legitimidade representada justamente pela incapacidade estatal de atender simultaneamente essa ampla gama de exigências. Para superar sua própria deficiência, o Estado descentraliza parte de seus poderes em favor de instituições políticas locais e regionais. Essa transferência decorre de duas tendências convergentes: de um lado, dada a "diferenciação territorial entre as duas instituições do Estado, as identidades das minorias regionais e nacionais conseguem se manifestar com maior desenvoltura em níveis local e regional." 62. Por outro lado, observa-se que "os governos nacionais tendem a concentrar-se na administração dos desafios impostos pela globalização da riqueza, da comunicação, e do poder." ${ }^{\text {, }}$, sendo que a maior consequência dessa atitude é a permissão estatal para que os "escalões inferiores do governo assumam a responsabilidade pelas relações com a sociedade, tratando das questões do dia-a-dia, com o objetivo de reconstruir sua legitimidade por meio da descentralização do poder." ${ }^{164}$.

A retração estatal e a abertura de espaços cada vez maiores fomenta o surgimento de entidades não governamentais e autossuficientes nascidas em comunidades locais para as quais o cidadão se

59 WOLKMER, A.C. Pluralismo jurídico: fundamentos de uma nova cultura no direito, p. 323-324.

60 WOLKMER, A.C. Pluralismo jurídico: fundamentos de uma nova cultura no direito, p. 323-324.

61 FARIA, J. E.; KUNTZ, R. Estado, sociedade e direito: qual o futuro dos direitos? Estado, mercado e justiça na reestruturação capitalista, p. 71 e 210.

62 CASTELLS, M. 1999, O poder da identidade. A era da informação: economia, sociedade e cultura, p. 317.

63 CASTELLS, M. 1999, O poder da identidade. A era da informação: economia, sociedade e cultura, p. 317.

64 CASTELLS, M. 1999, O poder da identidade. A era da informação: economia, sociedade e cultura, p. 317. 


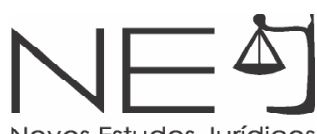

volta buscando refúgio frente à incapacidade estatal. Assim, se o Estado cede/perde espaço, legitima a atuação dessas entidades (re)construídas a partir de forças sociais ou políticas (que poderão ser religiosas, territoriais ou étnicas ${ }^{65}$ ) e que assumem o controle estatal a fim de transformá-lo na sua expressão exclusiva. Então, verifica-se a existência de Estados esvaziados lutando com todas as suas forças para reconstruir sua legitimação e instrumentalidade.

Então, o Direito inoficial esbarra no contraponto do direito oficial no qual o Estado tem o monopólio da violência legítima e do direito, dispondo de uma organização burocrática de larga escala, centralizada e centralizadora; a cidadania é atribuída a indivíduos pelo Estado de que são nacionais, pelo que em princípio não há cidadania sem nacionalidade e vice-versa; os cidadãos são formalmente iguais e estão todos igualmente sujeitos ao poder de império do Estado. Porém, essa é uma das características da crise funcional do Estado: possuir o monopólio da violência legítima, mas não o monopólio da produção do Direito. Pelo contrário, "existe na sociedade uma pluralidade de ordens jurídicas, com diferentes centros de poder a sustentá-los, e diferentes lógicas normativas."66.

\section{É neste sentido que Paolo Grossi ${ }^{67}$ se posiciona ao referir que}

a forçada colocação do direito na sombra do Estado - ente unitário, criatura monocrática essencialmente vocacionada ao controle da pluralidade social e à contração da pluralidade à unidade - provoca uma simplificação do universo jurídico. Não se pode contentar com a superfície plana da validade a que o formalismo jurídico moderno nos vinculou e condenou, mas se deve chegar a recuperar o extrato até agora subterrâneo da efetividade. E será o resgate de um substancial pluralismo jurídico, e será o reencontro de uma riqueza perdida ou pelo menos esquecida.

Essa riqueza perdida/esquecida, essa pluralidade de ordens não legitimadas pelo Estado, muitas vezes inoficiais, é composta de poderes de fato cuja pretensão nem sempre é a oposição direta ao Estado. No entanto, alguns desses poderes são forças políticas que, consequentemente, se transformam em concorrentes diretos daqueles oficialmente estabelecidos, pois, como eles, pretendem impor a sua concepção de direitos e de vida coletiva à comunidade inteira. Dessa forma:

La vita degli stati vi è sempre stato un conflitto tra poteri di fatto e poteri costituiti. Ma nello stato democratico attuale, la novità è che vi è una certa legittimazione nell'attribuzione di questi poteri a ordinamento che però sono soltanto in maniera parziale riconosciuti come tali. ${ }^{68}$

65 Neste sentido sugere-se a leitura de PREVE, Daniel Ribeiro. Pluralismo jurídico e interculturalidade: os sistemas jurídicos indígenas latino-americanos e as formas alternativas na resolução de conflitos. Santa Cruz do Sul: Essere nel Mondo, 2019.

66 BAUMAN, Z. Amor líquido: sobre a fragilidade dos laços humanos. Tradução de Carlos Alberto Medeiros. Rio de Janeiro: Jorge Zahar, 2004, p. 338-339.

67 GROSSI, Paolo. Absolutismo jurídico (ou: da riqueza e da liberdade do historiador do Direito). Revista do Direito GV2. v. 1 n. 2, p. 191-200, Jun./Dez. 2005.

68 GERIN, G. La crisi dello Stato Democratico. Padova: CEDAM, 1974, p. 66. 


\section{CONSIDERAÇÕES FINAIS}

O pluralismo jurídico é uma das consequências da retração do Estado diante do surgimento de novas forças (paralelas) que fomentam a criação de um direito supraestatal. Essas novas forças nascem da autodeterminação de organizações sociais e de sua intensa participação nas decisões dos órgãos públicos. Consequentemente, avista-se um pluralismo produto da ruptura de mitos estatais sacralizados, expressão direta dos reais interesses, da experiência e das exigências das complexas relações histórico-sociais. Assim, avista-se o surgimento de um modelo social composto de vários grupos ou centros de poder, que podem inclusive estar em conflito entre si. Esses grupos se auto atribuem a tarefa de limitar e controlar o centro de poder dominante, que historicamente se identifica com o Estado. O pluralismo é uma forma de oposição a concentração e unificação de poder, que caracteriza a formação estatal moderna.

Tradicionalmente, para tratar os conflitos nascidos da sociedade, o Estado, enquanto detentor do monopólio da força legítima, utiliza-se do Poder Judiciário. O juiz concentra e unifica a legitimidade e o poder estatal devendo, então, decidir os litígios porque o sistema social não suportaria a perpetuação do conflito. A legitimidade estatal de decidir os conflitos nasce, assim, do contrato social no qual os homens outorgaram a um terceiro - juiz- representante do Estado - o direito de fazer a guerra em busca da paz. Porém, o contrato social não trouxe o fim dos conflitos e nem mesmo significou o extermínio das práticas de autotutela. O que se verifica atualmente é a existência de um espaço social periférico que, na ausência estatal torna-se campo fértil para o surgimento e desenvolvimentos de forças paralelas que, além de criar, impõe um direito marginal, na maioria das vezes nada democrático e imposto pela força e pela coação.

Nestes termos, as interações humanas passam a ser permeadas por grupos que se instituem e legitimam socialmente atuando na administração e resolução de conflitos complexos, individuais e coletivos, em tempo razoável e oferecendo respostas adequadas ainda que muitas vezes carentes de juridicidade. Esse policentrismo na administração dos conflitos aponta para mecanismos estatais e extraestatais. Na condição de mecanismos estatais avista-se o Poder Judiciário e as ferramentas a ele atreladas principalmente diante das últimas mudanças legislativas ${ }^{69}$, tais como a mediação e a conciliação (direito oficial). Como mecanismos extraestatais avista-se a resolução de conflitos pela própria comunidade (direito inoficial) o que pode acontecer de maneira pacífica e democrática ou então pela imposição do mais forte, com o uso violência (ilegítima uma vez que se trata daquela não monopolizada pelo Estado).

Concluindo e respondendo ao questionamento motivador da pesquisa, pode-se observar que, à medida que diminui a presença e a participação do Estado em determinados espaços sociais, a tendência é o aumento da organização e da aplicação de regras criadas pelo cidadão objetivando o tratamento de conflitos. Tais hipóteses oferecem soluções céleres através de procedimentos informais, mas, muitas vezes, impõem decisões pela ameaça e aplicação da violência. O problema se instala diante da ausência do Estado ou da dificuldade de aplicação do Direito oficial que, muitas

69 Lei 13.105/2015 (novo Código de Processo Civil -NCPC) e lei 13.140/2015 (marco legal da mediação). 
vezes, depende de um moroso procedimento legislativo para ser instituído e de outro tão demorado quanto para ser aplicado. Cansados de esperar, muitas vezes os indivíduos aplicam suas próprias regras, ainda que ausentes de oficialidade.

\section{REFERÊNCIAS DAS FONTES CITADAS}

ARNAUD, A.-J. Da regulação pelo direito na era da globalização. Anuário de direito e globalização. A soberania. Programa interdisciplinar Direito e Globalização - UERJ. Coordenação de Celso de Albuquerque Mello. Rio de Janeiro: Renovar, 1999b.

ARNAUD, A.-J. O Direito entre Modernidade e Globalização - Lições de Filosofia do Direito e do Estado. Tradução de Patrice Charles Wuillaume. Rio de Janeiro: Renovar, 1999a.

BAUMAN, Z. Amor líquido: sobre a fragilidade dos laços humanos. Tradução de Carlos Alberto Medeiros. Rio de Janeiro: Jorge Zahar, 2004.

BOBBIO, N. As ideologias e o poder em crise. Tradução de João Ferreira. 4. ed. Brasília: UnB, 1999.

BOBBIO, N. Pluralismo. In: BOBBIO, N.; MATTEUCCI, N.; PASQUINO, G. Dicionário de Política. Tradução Carmen V. Varriale et al. Coordenador e tradutor João Ferreira; revisão geral João Ferreira e Luís Guerreiro Pinto Cascais. 12. ed. Brasília: Editora Universidade de Brasília, 2004, p. 240-262.

CAPELLA, J. R. Fruto Proibido: uma aproximação histórico-teórica ao Estudo do Direito e do Estado. Porto Alegre: Livraria do Advogado, 2002.

CASSESE, S. La crisi dello Stato. Toma-Bari: Laterza \& Figli Spa, 2002.

CASTELLS, M. O poder da identidade. A era da informação: economia, sociedade e cultura. Tradução de Klauss Brandini Gerhardt. 3. ed. São Paulo: Paz e Terra, 1999.

COUTINHO, C. N. Notas sobre o pluralismo. Conferência apresentada no Encontro Nacional da Associação Brasileira de Ensino do Serviço Social. [S.I.;S.n.], 1990.

EHRLICH, E. Fundamentos da sociologia do direito. Brasília: UnB, 1986.

FARIA, J. E.; KUNTZ, R. Estado, sociedade e direito: qual o futuro dos direitos? Estado, mercado e justiça na reestruturação capitalista. São Paulo: Max Limonada, 2002.

GARCÍA-PELAYO, M. Las transformaciones del Estado contemporâneo. Madrid: Alianza Universidad, 1996.

GERIN, G. La crisi dello Stato Democratico. Padova: CEDAM, 1974.

GROSSI, Paolo. Absolutismo jurídico (ou: da riqueza e da liberdade do historiador do Direito). Revista do Direito GV2. v. 1 n. 2, p. 191-200, Jun- Dez 2005.

GROSSI, Paolo. Da sociedade de sociedades à insularidade do estado entre medievo e idade moderna. Revista Seqüência, n. 55, p. 9-28, dez. 2007.

GURVITCH, G. Tratado de Sociologia. 2. ed. Rio de Janeiro: Iniciativas Editoriais, 1968.

MARRA, R. Max Webber: razionalità formale e razionalità materiale del diritto. In: Sociologia del diritto. Rivista quadrimestrale fondata da Renato Treves. Università Degli Studi di Milano. Milano, XXXII/2005/2-3, p. 69. 
MODUGNO, F. Pluralità degli ordinamenti. In: Enciclopedia del diritto. XXXIV Pluralità-premeditazione. Varese: Giuffrè, 1985, p. 200-270.

MORAIS, J. L. B. de. A idéia de direito social. O pluralismo Jurídico de Georges Gurvitch. Porto Alegre: Livraria do Advogado, 1997.

NISBET, R. Os filósofos sociais. Tradução de Yvette Vieira Pinto de Almeida. Brasília: UnB, 1999.

NISBET, R. Os filósofos sociais. Tradução de Yvette Vieira Pinto de Almeida. Brasília: UnB, 1982.

PREVE, Daniel Ribeiro. Pluralismo jurídico e interculturalidade: os sistemas jurídicos indígenas latinoamericanos e as formas alternativas na resolução de conflitos. Santa Cruz do Sul: Essere nel Mondo, 2019.

REALE, M. Teoria do Direito e do Estado. 4. ed. São Paulo: [s. ed.], 1984.

RESTA, E. Diritto Vivente. Roma: Laterza, 2008.

SANTOS, B. de S. O discurso e o poder. Ensaios sobre a sociologia da retórica jurídica. Porto Alegre: Sérgio Antônio Fabris, 1988.

SANTOS. Jorge Luis Ribeiro dos. Povos indígenas, Direito e Estado: rompendo cânones do integracionismo jurídico. Revista Novos estudos Jurídicos - NEJ, v. 20, n. 1(jan/abr.2015)

SPENGLER, Fabiana Marion. Os (des)caminhos do Estado e da Jurisdição. Santa Cruz do Sul: Essere nel Mondo: 2017

STRECK, L. L.; MORAIS, J. L. B. de. Ciência política e teoria geral do Estado. 8. ed. Porto Alegre: Livraria do Advogado, 2013.

WOLKMER, A. C. Instituições e pluralismo na formação do direito brasileiro. Teoria do Direito e Estado. (Org. Leonel Severo Rocha). Porto Alegre: Sérgio Antonio Fabris, 1994.

WOLKMER, A.C. Pluralismo jurídico. In: BARRETO, Vicente de Paulo. Dicionário de Filosofia do Direito. Rio de Janeiro/São Leopoldo: Renovar/Editora Unisinos, 2006, p.136-157.

WOLKMER, A.C. Pluralismo jurídico: fundamentos de uma nova cultura no direito. 3. ed. São Paulo: Alfa Omega, 2001.

ZANGHÍ, C. Diritto delle organizzazioni internazionali. Torino: [s. ed.], 2001.

Recebido em: 28/07/2020

Aprovado em: $11 / 12 / 2020$ 